Faculdade de Ciências Econômicas UFRGS
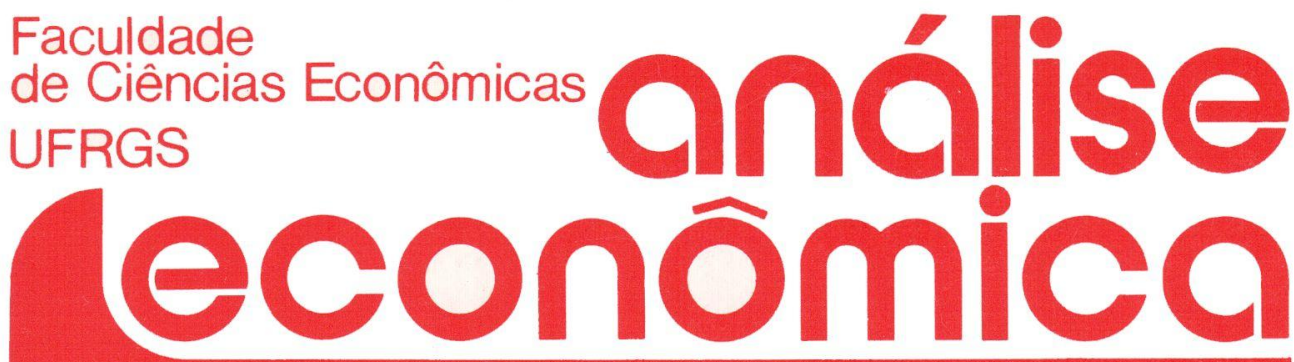

nesta edição:

- PRODUÇÃO DE ÁLCOOL E EMPREGO Otto G. Konzen e Juvir L. Mattuella

- NECESSIDADE DE PENSAR E CONSTRUIR O PÓS-CRISE Marcus Vinicius Pratini de Moraes

- CONTAS EXTERNAS

Fernando Ferrari Filho

- FETICHISMO

Leda Maria Paulani

- CRISE DO CAPITALISMO MUNDIAL Beki Morón de Macadar

- EXPANSÃO CAFEEIRA NO ESPÍRITO SANTO José L. Celin
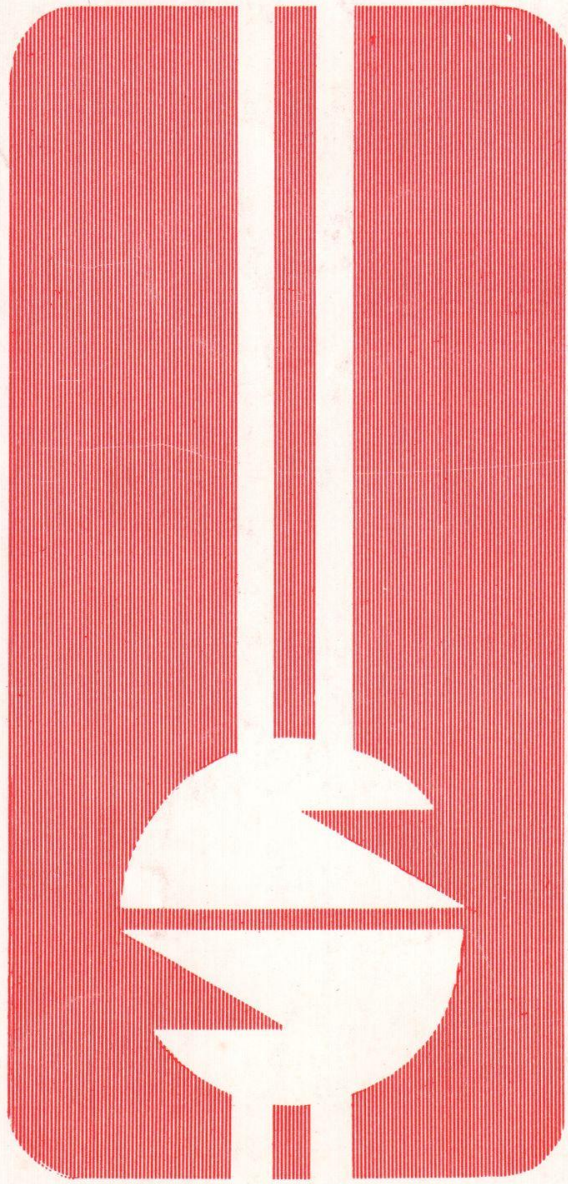
DIRETOR DA FACULDADE DE CIÉNCIAS ECONOMMICAS:

Prof. Antonio Carlos Santos Rosa/Prof. Edgar Irio Simm

VICE-DIRETOR:Prof. Nelson Rokembach/Prof. Walter Meucci Nique

CHEFE DO DEPARTAMENTO DE CIẼNCIAS ECONÔMICAS:

Prof. Renato Batista Masina

CONSElHo EdITORIAL: Prof. Pedro Cezar Dutra Fonseca (Presidente)

Prof. Achyles Barcelos da Costa

Prof. Carlos Augusto Crusius

Prof. Claudio Francisco Accurso

Prof. Edgar Augusto Lanzer

Prof. Ernani Hickmann

Prof. Nali de Jesus de Souza

Prof. Nuno Renan Lu de Figueiredo Pinto

Profa Otilia Beatriz Kroeff Carrion

Prof. Roberto Camps Moraes

Profạ Yeda Rorato Crusius

FUNDADOR: Prof. Antonio Carlos Santos Rosa

ANALISE ECONÔMICA publica dois números anuais, nos meses de março e novembro. O preço da așsinatura para 1985 é $\mathrm{Cr} \$ 6.000,00$, a ser pago através de cheque nominal para "Faculdade de Ciências Econômicas - UFRGS". Aceita-se permuta com revistas congêneres. Aceitam-se, também, livros para elaboração de resenhas ou recensões.

Toda a correspondência, material para publicação, assinaturas e permutas devem ser dirigidas a:

Prof. PEDRO CEZAR DUTRA FONSECA

Revista Análise Econômica

Avenida João Pessoa, $52-3 \%$ andar

90.000 - Porto Alegre (RS) - Brasil 


\title{
A CRISE DO CAPITALISMO MUNDIAL *
}

\author{
BEKY MORÓN DE MACADAR
}

\section{INTRODUÇÃO}

A economia mundial e a distribuição das atividades produtivas entre os países e entre os setores passam atualmente por um complexo processo de transformações. Esse processo está introduzindo importantes modificações na estrutura produtiva, não só dos países capitalistas industrializados, mas também dos subdesenvolvidos.

O esgotamento de um esquema de acumulação que assegurou uma prolongada fase de desenvolvimento do capitalismo mundial parece estar dando lugar a um novo esquema de acumulação caracterizado por um acelerado processo de internacionalização do capital liderado pelas empresas transnacionais, e uma realocação da produção industrial que supõe ajustamentos na divisão internacional do trabalho com a finalidade de aproveitar a mão-de-obra barata das áreas subdesenvolvidas.

Existem alguns elementos que obrigam a ter muita cautela nas previsões da evolução desta última tendência. As novas fronteiras que se abrem no campo da eletrônica, da informática e das

\footnotetext{
* Este artigo corresponde à Parte II do trabalho de diplomação intitulado "A Rearticula. ção do Capitalismo Mundial", apresentado pela autora em novembro de 1983 na Faculdade de Ciências Econômicas da UFRGS. A Parte I daquele trabalho foi dedicada a uma análise aprofundada da crise do ponto de vista teórico e do ponto de vista histórico, que proporciona sustentação teórica e empírica à interpretação da crise ora apresentada.
}

\begin{tabular}{|l|l|l|l|l|}
\hline ANÁLISE ECONÔMICA & ANO 2 & No 4 & NOV./1984 & p.47-66 \\
\hline
\end{tabular}


aplicações industriais da biologia poderão dar um novo impulso ao crescimento econômico e à produtividade. Portanto a difusão da automação, visto o enorme incremento na produtividade que ela possibilita, permitiria aos países industrializados recuperar antigas indústrias atraídas pela mão-de-obra barata dos subdesenvolvidos. Isso poderia frear a redistribuição das atividades produtivas e aprofundar a dependência dos países subdesenvolvidos.

Portanto, uma análise da problemática nacional e das saídas para a crise brasileira deve, inevitavelmente, levar em conta a evolução do capitalismo a nível mundial, a fim de elaborar uma estratégia de desenvolvimento adequada, em função das necessidades reais da população.

\section{1 - CARACTERISTICAS DA CRISE ATUAL}

A internacionalização da produção, que no modo de produção capitalista leva necessariamente a uma concentração e centralização internacional do capital, torna cada vez mais inoperantes as tentativas dos estados imperialistas nacionais de aplicar políticas anticíclicas dentro das próprias fronteiras nacionais. De fato, "o processo de transnacionalização do capital foi acompanhado de uma dependência monetária e financeira das economias do centro relativamente aos mercados mundiais (em especial o de eurodivisas), a organismos internacionais (FMI, Banco Mundial) dominados por alguns Estados (particularmente os EUA), e a grupos financeiros gigantescos. Segue-se que os Estados são incapazes de gerir os capitais líquidos internacionais e as taxas de câmbio, resultando quase inoperantes as políticas de regulação conjuntural, principalmnte a monetária, a de preços, a fiscal e, portanto, o sistema de planificação". 1

Para Ernest Mandel ${ }^{2}$ a história do capitalismo é a história de uma sucessão de longos períodos de acumulação acelerada e desacelerada (que ele denomina de "ondas longas"), intimamente liga. dos com as flutuações na taxa de lucro. De acordo com sua periodização, a atual crise do capitalismo teve início em 1967, com um período depressivo de longo prazo sucedendo a um periodo de crescimento econômico sustentado entre 1940-45 e 1966.

1 - BENAKOUCHE, Rabah. Inflação e Crise na Economia Mundial. Petrópolis, Vozes, 1981. p. 103.

2 - MANDEL, Ernest. O Capitalismo Tardio, São Paulo, Abril, 1982. p. 92-3. 
Nos períodos de crescimento econômico, as fases de recessão são mais curtas e menos profundas, e as fases de reativação e de boom mais prolongadas e prósperas. Pelo contrário, nos períodos de depressão, também ocorrem momentos de crescimento, mas a tendência depressiva é dominante e as reativações são mais curtas e menos expansivas.

A principal técnica utilizada para tentar controlar o ciclo e moderar a amplitude das crises periódicas de superprodução consistiu na expansão do crédito e na expansão monetária. Mas as políticas anticíclicas resultaram fatalmente inflacionárias.

"O déficit financeiro - em outras palavras, o uso de déficits orçamentários com a finalidade de criar uma 'demanda monetária efetiva' adicional - foi a estratégia de longo prazo adotada pelo Estado. O papel dos gastos públicos como principal fonte da inflação tornou-se ainda mais pronunciado na Segunda Guerra Mundial. Mas depois da guerra, na nova 'onda longa com tonalidade expansionista', os gastos estatais efetivos, embora ainda fossem substanciais, acabaram por assumir importância secundária na dinâmica da inflação permanente. A partir daí, a principal fonte de inflação passou a ser o saque a descoberto em contas correntes, concedido pelos bancos ao setor privado, e coberto pelos bancos centrais e pelos governos em outras palavras, crédito para a produção de empresas capitalistas e crédito ao consumidor particular (sobretudo para a compra de casas e bens de consumo duráveis). Por conseguinte, a inflação permanente é hoje a inflação permanente na moeda escritural, ou da forma de criação de dinheiro própria do capitalismo tardio para facilitar a reprodução ampliada a longo prazo (meios adicionais para a realização da mais-valia e para a acumulação de capital)."'3

Analisamos, em continuação, uma série de indicadores que permitem calibrar a intensidade e generalização da crise atual.

\section{1 - Inflação}

No período 1950-65, a média das taxas anuais de inflação de dez países industrializados se situava entre os 2 e $3 \%$ anuais (exceto o período relacionado com a Guerra da Coréia); no período

3-MANDEL, Ernest. Op. cit., p. 295. 
1966-70, a taxa média era de $4,1 \%$ ao ano; e no período $1971-75$, de $8 \%$ ao ano. ${ }^{4}$ Sem dúvida, o que caracteriza a última década é a aceleração do ritmo de inflação: a partir de 1974, a média das taxas anuais de inflação dos países da OCDE alcançou os dois dígitos (vide Tabela 1).

TABELA 1 - AUMENTO DOS PREÇOS DE CONSUMO

(porcentagem com relação ao per fodo precedente, em taxas anuais, corrigidas quanto as variações sazonais)

\begin{tabular}{l|r|r|r|r|r|r|c}
\hline & 1970 & 1974 & 1975 & 1980 & 1981 & 1982 & 1983 (a) \\
\hline Estados Unidos & & & & & & & \\
Japão & 5,7 & 11,8 & 8,0 & 12,8 & 10,3 & 5,9 & 4,25 \\
Alemanha & 6,9 & 24,9 & 9,4 & 8,2 & 4,9 & 2,9 & 2,0 \\
Suécia & 3,8 & 6,8 & 5,8 & 5,4 & 5,9 & 5,3 & 3,0 \\
Reino Unido & 7,7 & 9,4 & 11,1 & 14,2 & 9,0 & n.d. & n.d. \\
Itália & 7,3 & 17,8 & 26,0 & 15,9 & 12,0 & 8,0 & 6,0 \\
Canadá & 5,0 & 22,7 & 13,3 & 21,7 & 19,6 & 16,7 & 15,25 \\
Todos os parses da OCDE & 2,6 & 11,5 & 10,6 & 10,9 & 11,5 & 10,5 & 6,25 \\
\hline
\end{tabular}

(a) Estimado n.d. Năo-disponível

Fontes: Perspectiva Internacional, no 3, julho-agosto 1982, p. 16, para todas as cifras, salvo para os anos de 1982 e 1983, que vêm da Conjuntura Econômica, V. 37, nọ 8, agosto 1983.

\section{2 - Produção industrial}

A partir de 1967, aparecem as primeiras manifestações de uma redução na produção industrial mundial, o que leva Mandel a identificar a passagem de uma onda longa com tonalidade expansionista a uma onda longa com tonalidade de estagnação (vide Tabela 2).

4-BENAKOUCHE, Rabah. Op. cit., p. 103. 
TABELA 2 - PERCENTAGEM COMBINADA ANUAL DO CRESCIMENTO DA PRODUÇÃO INDUSTRIAL

\begin{tabular}{l|c|c}
\hline PAISES & $1947-1966$ & $1966-1975$ \\
\hline EUA & 5,0 & 1,9 \\
Os "Seis" iniciais da CEE & 8,9 & 4,6 \\
Japão & 9,6 & 7,9 \\
Reino Unido & 2,9 & 2,0 \\
\hline
\end{tabular}

Fonte: E. Mandel, O Capitalismo Tardio, p. 99.

Dois períodos de aguda recessão se destacam na onda longa com tonalidade de estagnação: 1974/1975 e 1980/1982.

Em 1975, as cinco grandes potências capitalistas sofreram fortes quedas nos investimentos produtivos: $-13 \%$ para os EUA, $-4 \%$ para o Japão, $-8 \%$ para a Grã-Bretanha, -3\% para a França. A Alemanha, em 1975, experimentou uma ligeira recuperação da queda que sofrera em 1974 (-10\%). Somente em 1977 o crescimento dos investimentos destas economias consegue voltar ao ritmo dos anos 1972/73 (vide Tabela 3).

TABELA 3 - INVESTIMENTOS PRODUTIVOS (MÁQUINAS E BENS DE EQUIPAMENTO) E ACRÉSCIMOS ANUAIS (em moeda constante)

\begin{tabular}{l|c|c|c|c|c|c|c|c}
\hline & 1971 & 1972 & 1973 & 1974 & 1975 & 1976 & 1977 & 1978 \\
\hline USA - bilhões & 66,3 & 74,3 & 85,5 & 88,1 & 75,6 & 80,6 & 89,8 & 98,0 \\
de $\$ 72$ & $-1 \%$ & $+12 \%$ & $+15 \%$ & $+3 \%$ & $-13 \%$ & $+5 \%$ & $+11 \%$ & $+9 \%$ \\
Japão-bilhões & 15.108 & 16.238 & 18.893 & 17.061 & 16.313 & 16.500 & 16.720 & 17.500 \\
de ienes 70 & $-3 \%$ & $+7 \%$ & $+16 \%$ & $-10 \%$ & $-4 \%$ & $+1 \%$ & $+1 \%$ & $+5 \%$ \\
Reino Unido- & 4.453 & 4.481 & 4.971 & 5.176 & 4.750 & 4.706 & 4.743 & 5.100 \\
bilhões de £ 70 & $-2 \%$ & $+0,6 \%$ & $+11 \%$ & $+4 \%$ & $-8 \%$ & $-1 \%$ & $+0,8 \%$ & $+7 \%$ \\
França - bilhões & 196 & 210 & 222 & 223 & 217 & 225 & 224 & 224 \\
de F. 70 & $+7 \%$ & $+7 \%$ & $+6 \%$ & $+0,5 \%$ & $-3 \%$ & $+4 \%$ & $-0,6 \%$ & - \\
RFA - bilhões & 72,5 & 71,7 & 72,3 & 64,9 & 65 & 69,3 & 74,7 & 79 \\
de DM 70 & $+6 \%$ & $-1 \%$ & $+1 \%$ & $-10 \%$ & - & $+7 \%$ & $+8 \%$ & $+6 \%$ \\
\hline
\end{tabular}

Fonte: Contabilidades nacionais, citado por R. Benakouche, Inflação e Crise na Economia Mundial, p. 128.

A amplitude das recessões de $1974-75$ e de $1980-82$ nos EUA aparece claramente na evolução das taxas de utilização da capacidade de produção instalada (vide Tabela 4). 


\begin{tabular}{l|c|c}
\hline & ANO & $\%$ \\
\hline & 1966 & 92,0 \\
& 1967 & 78,0 \\
& 1968 & 87,7 \\
& 1969 & 86,5 \\
& 1970 & 78,0 \\
& 1971 & 75,0 \\
49 trimestre & 1972 & 78,5 \\
Março & 1973 & 83,0 \\
Junho & 1974 & 78,0 \\
Dezembro & 1975 & 65,0 \\
Agosto & 1975 & 68,5 \\
Dezembro & 1975 & 73,5 \\
Agosto & 1980 & 72,2 \\
Dezembro & 1980 & 78,1 \\
Janeiro & 1981 & 76,0 \\
\hline
\end{tabular}

Fonte: De 1966 a 1975, E Mandel, La Crisis, p. 32; de 1980 a 1982, Perspectiva Internacional, julho-agosto, 1982.

A baixa da produção industrial no período 1980-82 ocorre de forma praticamente simultânea em todos os grandes países imperialistas: República Federal Alemã, França, EUA, Itália, Canadá e Grã-Bretanha. Nem o Japão escapou de uma baixa, embora fosse menos golpeado que seus concorrentes. A magnitude da crise se faz sentir no caráter amplamente sincronizado da recessão: praticamente todas as potências imperialistas de menor importância participam do enfraquecimento da produção industrial. "Pela primeira vez, há uma queda na Áustria (em 1981, a produção ai diminui de dois por cento), na Bélgica (em 1980 e em 1981), na Dinamarca, na Noruega (1981), na Holanda (em 1980 e 1981), na Suécia (1981), na Suíça (início de 1982)". ${ }^{5}$

Assim como em 1975, as industrias mais atingidas pela recessão de 1980-82 foram a indústria automobilística, da construção civil, da siderurgia e da petroquímica. A indústria da construção

5-MANDEL, Ernest. 1980-1982: Segunda recessão generalizada do capitalismo internacional. Perspectiva Internacional, São Paulo, Aparte, 1(3):12, jul./ago. 1982. 
mecânica foi a que menos sofreu com a crise, mas mesmo setores de ponta como a indústria de semicondutores e dos microprocessadores foram atingidas pela recessão. ${ }^{6}$

\section{3 - O comércio internacional}

Durante dois anos consecutivos (1981-1982), o valor do comércio mundial registrou declínio em termos nominais. De acordo com estimativas preliminares, o total das exportações mundiais alcançou US $\$ 1.883 .800$ milhões em 1982, representando uma queda de $6,1 \%$ com relação ao ano anterior. ${ }^{7}$ Sem dúvida, as crescentes taxas de desemprego e os desequilibrios do balanço de pagamentos contribuíram para um fortalecimento do protecionismo.

Tanto na recessão de 1974-1975 quanto na de 1980-1982, ocorreu uma acentuada procura de "mercados de substituição". No primeiro ciclo, essa função foi desempenhada pelos países da OPEP (Organização dos Países Exportadores de Petróleo), pelos países socialistas "que assumem uma função de consumidores importantes por ocasião das situações de crise nas economias capitalistas" ${ }^{\prime 8}$ e por uma série de países coloniais (Ásia do Leste e do Sudeste).

No último periodo crítico, a recessão coincidiu com a crise de alguns países socialistas fortemente endividados, uma queda dos preços do petróleo, e, portanto, uma queda dos excedentes do balanço de pagamentos dos países da OPEP. Os "mercados de substituição" encolheram fortemente, e o peso da economia dos países da Asia Oriental e do Sudeste asiático, tais como Hong Kong, Cingapura, Coréia do Sul, Formosa, Malásia, etc., na economia capitalista internacional é reduzido demais para poder modificar sua dinâmica de conjunto.

\section{4 - Queda dos PNBs}

Entre 1959-60 e 1970-71, o PNB dos países da OCDE cresceu a uma média anual de $5,3 \%{ }^{-9}$ Na recessão generalizada de 1974-75, seu PNB caiu em 0,1\% ao ano, e na recessão de 1980-1982, a mé-

6 - Id., ibid., p. 12.

7 - BANCO CENTRAL DO BRASIL. Relatório 1982

8 - BENAKOUCHE, Rabah. Op. cit., p. 184.

9 - BANCO CENTRAL DO BRASIL. Relatórios. Apud BENAKOUCHE, Rabah. Op. cit., p. 126. 
dia de crescimento foi de $1,2 \%$ em 1980 e 1981 e uma queda de $0,5 \%$ em 1982. A gravidade da crise foi sentida por todas as grandes potências capitalistas, particularmente em 1975 e 1982 (vide Tabela 5).

Nem o Japão chega a configurar uma exceção. Sem dúvida, a taxa de crescimento mais elevada do Japão durante os últimos anos é essencialmente função de uma taxa de lucro mais elevada. Isso se explica, em primeiro lugar, pelo fato de que, mesmo nos casos de igualdade de produtividade, os salários japoneses são inferiores aos da Europa Ocidental e dos Estados Unidos e, em segundo lugar, pelo atraso abismal das despesas em previdência social. ${ }^{10}$ Mas o boom das exportações japonesas começa a se esgotar. O protecionismo acentuado pela recessão mundial afetou a expansão de suas vendas ao exterior, particularmente no setor automobilístico, e o Japão está enfrentando dificuldades em encontrar novos produtos de venda massiva para expandir as suas exportações.

\section{5 - Aumento do desemprego}

As cifras indicam um forte aumento do desemprego nos países industrializados. Na área da OCDE, os dados disponíveis revelam que $8,4 \%$ da força de trabalho estava desempregada em 1982, superando sensivelmente a taxa de $7,1 \%$ registrada em 1981 . O número médio de desempregados passou de 25 milhões para 29,9 milhões. As estimativas para o ano de 1983 são de 33,5 milhões, e as projeções para o ano de 1984 estimam 34,5 milhões de desempregados no âmbito da OCDE.

O crescimento do desemprego é mais intenso na Europa industrializada, onde se aproxima atualmente dos 18 milhões, em contraste com os 15,9 de 1982. Os países da OCDE que sofreram um crescimento mais acelerado do desemprego foram Canadá, Holanda, Estados Unidos e Alemanha. Atualmente, as taxas de desemprego mais elevadas são as da Espanha $(17,5 \%)$, Turquia (16\%), Holanda $(15,5 \%)$ e Bélgica (15\%). ${ }^{1}$

10 - MANDEL, Ernest. 1980-1982: Segunda recessão...., p. 12.

11 - TEIXEIRA, Ib. Economia mundial: anos de tormenta. Conjuntura Económica, Rio de Janeiro, FGV, $37(38): 148-155$, ago. 1983, 


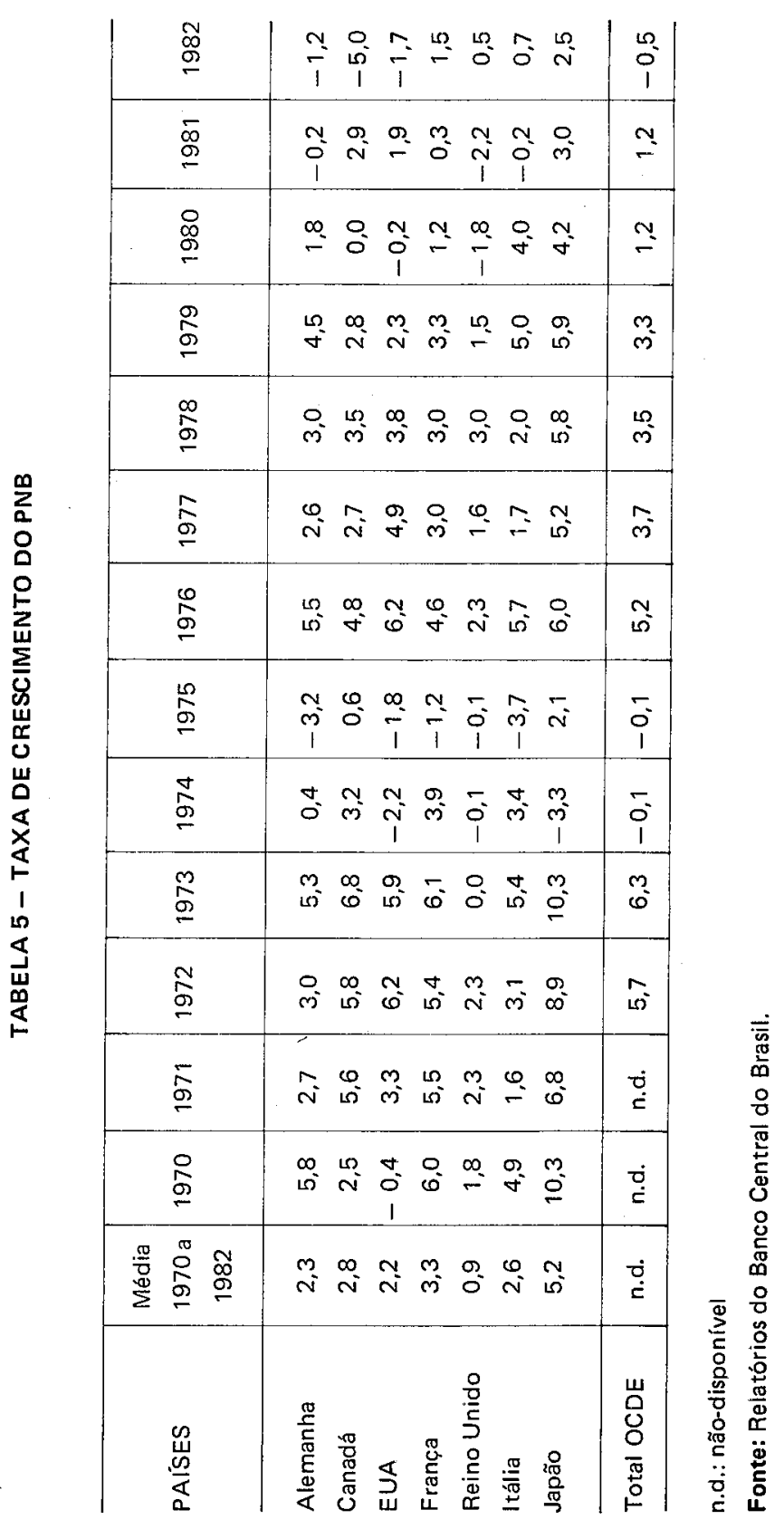




\section{6 - A amplitude da crise}

De acordo com Mandel, ${ }^{12}$ a crise atual é caracterizada como o ponto de convergência de cinco crises diferentes.

1 - Uma crise clássica de superprodução, limitada em sua duração e profundidade, com recurso ao financiamento do déficit e a uma ampliação do crédito a níveis inéditos. O crescente endividamento dos paises do Terceiro Mundo não produtores de petróleo é apenas um exemplo.

2 - A combinação de uma crise clássica de superprodução com a inversão da tendência de uma onda longa com tonalidade expansionista para uma onda longa com tonalidade de estagnação.

As rendas tecnológicas ${ }^{13}$ elevadas, que durante as décadas de cinqüenta e sessenta contribuíram para sustentar a taxa de lucro, têm declinado progressivamente ou desaparecido totalmente, e não há perspectivas de uma recuperação imediata.

3 - Uma nova fase da crise do sistema imperialista. Durante um quarto de século, o imperialismo teve que passar de um sistema colonialista de dominação direta para um tipo de dominação indireta; porém, essa passagem não representou nenhuma modificação radical da repartição da mais-valia mundial entre a burguesia dos países imperialistas e as burguesias dos países semicoloniais. A partir dos anos setenta, começa a se perfilar uma modificação das relações de força em prejuízo do imperialismo, que obrigou a modificar a repartição da mais-valia mundial, cedendo uma parte dela às classes dominantes dos países da OPEP.

4 - Uma crise social e política dos países imperialistas, resultado da ocorrência simultânea de uma depressão econômica com uma fase ascendente das lutas operárias e da politização dos trabaIhadores e, por outra parte, da tentativa de repassar para os trabaIhadores o peso da crise e da nova distribuição da mais-valia a nível mundial.

5 - A ocorrência dessas quatro crises simultaneamente com a crise estrutural da sociedade capitalista reativa a crise de todas as relações sociais burguesas e, principalmente, a crise das relações de produção capitalista. Nos períodos recessivos, a credibilidade do sistema capitalista como solução para um melhor nivel de vida, o pleno emprego e a consolidação das liberdades democráticas ficam sensivelmente abaladas.

12 - MANDEL, Ernest. La crisis 1974-1980. México, Era, 1980, p. 244-8.

13 - Lucros extraordinários favorecidos pelas práticas monopolistas, provenientes da aplicação de novas técnicas. 
A expansão acelerada do pós-guerra tinha levado a uma acumulação ampliada dos capitais que permitiram o rápido desenvolvimento da terceira revolução tecnológica (semi-automação, energia nuclear). Esta revolução tecnológica, ao facilitar um aumento substancial da mais-valia relativa e dos lucros extraordinários dos monopólios e oligopólios tecnologicamente avançados, proporcionando as chamadas "rendas tecnológicas", permitiu prolongar a expansão nas condições mais vantajosas para o capital: uma taxa de lucro elevada e um nível de vida real das massas trabalhadoras dos países capitalistas em evidente ascensão, traduzindo-se em um mercado em expansão. Uma parte importante da mais-valia se realizava nos próprios países imperialistas.

Mas a terceira revolução tecnológica, ao abrir o caminho para uma nova expansão, o que implica uma concentração crescente do capital, levou a um aumento intenso da composição orgânica do capital. Paralelamente, o longo período de pleno emprego fortaleceu o movimento operário. A partir dos anos sessenta, surgiram as primeiras dificuldades do capital para compensar o aumento da composição orgânica do capital com um aumento da taxa de maisvalia. Esta situação, combinada com a gradual erosão das rendas tecnológicas como conseqüência da difusão cada vez mais universal das inovações da terceira revolução tecnológica, determinou a inversão da "onda longa com tendência expansionista".

Para que se tenha uma visão mais completa desta fase típica de declínio da taxa de lucro média em alguns dos países capitalistas mais representativos, apresentamos as Tabelas 6,7 e $8 .{ }^{14} \bar{E}$ interessante destacar que esse declínio é claramente anterior à primeira crise do petróleo de 1973.

"Segundo os dados do Conference Board, as margens de benefício das sociedades anônimas americanas não-financeiras teriam passado de uma média de $20-22 \%$, no período 1959 . 66 , para $12 \%$ durante a recessão de $1970-71$, voltando a $15 \%$ durante o período do 'boom especulativo' de $1972-73$ e recaindo para $11-12 \%$ no in ício de $1975^{\prime \prime} .{ }^{15}$

Segundo os cálculos do semanário The Economist, ${ }^{16} \mathrm{o}$ índice dos lucros das empresas caiu de 100 em 1964 para menos de 60 em 1975, com uma queda marcante entre 1973 e 1975 (do índice 90 para um índice inferior a 60 ).

14 - MANDEL, Ernest. La crisis 1974-1980. p. $29-31$.

15 - MANDEL, Ernest. La crisis 1974-1980. p. 28.

16 - MANDEL, Ernest La crisis 1974-1980. p. 30. 
TABELA 6 - TAXA DE LUCRO (APÓS ELIMINAC̣ÃO DOS GANHOS COM REAVALIACÃO DOS ESTOQUES) A RESPEITO DO CAPITAL DAS SOCIEDADES NÄO-FINANCEIRAS NOS EUA

\begin{tabular}{l|c|c}
\hline \multirow{2}{*}{ ANOS } & PRÉ-TAXAČ̃̃O & PŌS-TAXAÇÃO \\
\hline $1948-1950$ & 16,2 & 8,6 \\
$1951-1955$ & 14,3 & 6,4 \\
$1956-1960$ & 12,2 & 6,2 \\
$1961-1965$ & 14,1 & 8,3 \\
$1966-1970$ & 12,9 & 7,7 \\
1970 & 9,1 & 5,3 \\
1971 & 9,6 & 5,7 \\
1972 & 9,9 & 5,6 \\
1973 & 10,5 & 5,4 \\
\hline
\end{tabular}

Fonte: William D. Norhaus: The Falling Share of Profit, in A.M. Okun and L. Perry (coord), Brookings Papers on Economic Activity, No. 1. 1974, The Brookings Institution.

TABELA 7 - TAXA DE LUCRO (APÓS ELIMINAÇÃO DOS GANHOS COM REAVALIAÇÃO DOS ESTOQUES) SOBRE OS HAVERES LIQUIDOS DAS SOCIEDADES INDUSTRIAIS E COMERCIAIS NO REINO UNIDO

\begin{tabular}{l|c|c}
\hline \multirow{2}{*}{ ANOS } & \multicolumn{2}{|c}{$\%$} \\
\hline $1950-1954$ & PRÉ-TAXAÇÃO & PÓS-TAXAÇÃO \\
$1955-1959$ & 16,5 & 6,7 \\
$1960-1964$ & 14,7 & 7,0 \\
$1965-1969$ & 13,0 & 7,0 \\
1968 & 11,7 & 5,3 \\
1969 & 11,6 & 5,2 \\
1970 & 11,1 & 4,7 \\
\hline
\end{tabular}

Fonte: Andrew Glyn and Bob Sutcliffe: British Capitalism, Workers and the Profit Squeeze, Londres, 1972, p. 66.

TABELA 8 - TAXA DE LUCRO (APÓS ELIMINAÇÃO DOS GANHOS COM REAVALIAÇAO DOS ESTOQUES) SOBRE OS HAVERES BRUTOS DAS EMPRESAS INDUSTRIAIS, COMERCIAIS E FINANCEIRAS NO JAPÄO

\begin{tabular}{|c|c|}
\hline ANOS & $\begin{array}{c}\% \\
\text { PRÉ-TAXAÇÃO }\end{array}$ \\
\hline 1967 & 14,0 \\
\hline 1968 & 14,7 \\
\hline 1969 & 14,3 \\
\hline 1970 & 14,7 \\
\hline 1971 & 14,2 \\
\hline 1972 & 13,0 \\
\hline 1973 & 10,9 \\
\hline 1974 & 11,9 \\
\hline
\end{tabular}

Fonte: OCDE: Pour le plein emploi la stabilité des prix, Informe McCracken, Paris, 1977. 
De uma maneira geral, podemos afirmar com Mandel que "a recessão foi provocada e se prolongou sob o efeito de uma baixa taxa média de lucro, combinada com uma queda dos investimen. tos produtivos". ${ }^{17} \mathrm{~A}$ crise atual provém de uma incapacidade crescente do sistema em manter seu ritmo de acumulação de capital.

O papel do Estado tem se ampliado substancialmente no capitalismo moderno e contribuiu para o prolongado auge do pósguerra. As principais contribuições do governo para sustentar a demanda efetiva e os benefícios à indústria foram as despesas com armamentos e um amplo desenvolvimento do crédito para favorecer a expansão interna das empresas. O Estado, tomando sob seus cuidados uma determinada massa de capitais, contribuiu com o financiamento público para elevar a massa e a taxa de lucros do capital monopolista. Portanto, "os setores de atividades nos quais tem se desenvolvido o capital público (mineração, eletricidade, aeronáutica, transportes, energia atômica, etc.) são setores que pesam fortemente sobre a taxa de lucros geral, em função de uma alta composição orgânica do capital. Isto significa que eles não recebem a parte da mais-valia social correspondente à sua importância e conseqüentemente a taxa de lucros dos monopólios dela é acrescida". ${ }^{18}$

A mais-valia produzida pelo setor público e dentro dele é transferida para os monopólios sob diversas formas: tarifas muito baixas dos serviços do setor público, encomendas regulares de equipamentos a preços compensadores, etc. A estas modalidades devem ser acrescentados outros tipos de beneficios que os monopólios obtêm em matéria de subsídios, bonificações, benefícios fiscais, etc.

O sistema de crédito ao consumo permitiu superar a médio prazo uma das contradições básicas do sistema capitalista: a necessidade de aumentar o poder de compra para estimular a demanda efetiva e a necessidade de comprimir os salários para continuar extraindo mais-valia. Comprometendo as rendas futuras, consegue-se o escoamento da produção presente.

Obviamente, a maioria dos instrumentos de expansão da demanda utilizados pelo Estado são inflacionários e só conseguiram solucionar os problemas da realização por um certo tempo, mas as contradições têm aumentado, e o mundo entrou numa fase de estagnação da qual fica cada vez mais difícil sair. Com uma infla-

17 - MANDEL, Ernest. 1980-1982: Segunda recessão..., p. 12.

18 - BENAKOUCHE, Rabah. Op. cit., p. 77. 
ção desenfreada, ao lado de um desemprego crescente, as políticas anticíclicas dos anos de pós-guerra são cada vez mais ineficazes.

\section{7 - O consumo improdutivo}

Para James F. Becker, a estagflação (estagnação econômica acompanhada de inflação) "é um estado cuja causa essencial é um excessivo consumo improdutivo" 19 Entende-se por consumo improdutivo "qualquer utilização do produto excedente para qualquer outro fim que não seja a manutenção ou ampliação da escala de insumo produtivo", ${ }^{20}$ isto é, qualquer uso do produto excedente que não contribui para o processo de reprodução econômica básica.

"A taxa de consumo improdutivo, U/V, é a razão entre o consumo improdutivo e o capital variável que gera o excedente. A razão entre a taxa de consumo improdutivo e a taxa de mais-valia apresenta sempre a fração do excedente social que está sendo improdutivamente consumida: $U / V \div S / V=U / S$. Sempre que a taxa de consumo improdutivo é positiva, o efeito consiste em puxar a taxa de acumulação para baixo do que poderia ser designado como seu máximo tecnicamente factível." ${ }^{21}$ (Vide gráfico 1)

Poderia se perguntar por que os capitalistas persistem em efetuar investimentos em projetos que elevam relativamente a taxa de consumo improdutivo quando uma elevação nessa taxa diminui a taxa real de lucro. Provavelmente porque o retardamento no aumento da taxa de crescimento do sistema facilita a realização dos lucros, uma vez que reduz também a taxa requerida de aumento na demanda agregada.

Um exemplo extremo disso seria o caso da guerra, momento em que o consumo improdutivo se aproxima do seu máximo, e a realização dos lucros está garantida pelos gastos do governo.

Nos intervalos de expansão, dado que uma parcela do excedente de cada período é consumida improdutivamente, gera-se um processo de demanda para os insumos produtivos e, conseqüentemente, elevam-se os preços desses insumos.

19 - BECKER, James F. Economia Politica Marxista. Rio de Janeiro, Zahar, 1980. p. 225.

$20-$ Id. ibid, p. 98.

21 - Id, ibid., p.99. 


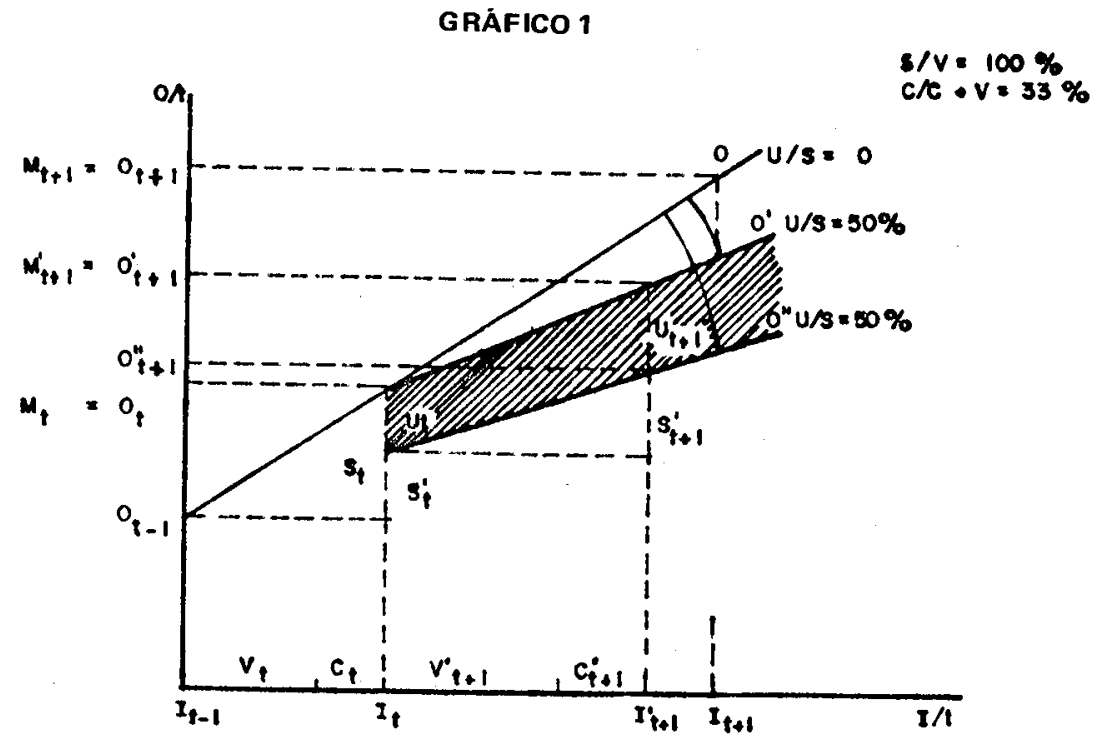

Fonte: James F. Becker. Economia Política Marxista, p. 100.

A linha $\mathrm{O}_{\mathrm{U} / \mathrm{S}}=\mathrm{O}$ mostra a taxa de acumulação no seu máximo tecnicamente factível. Nesse caso, o consumo improdutivo seria igual a zero e a totalidade do excedente consumido produtivamente. Supondo que a fração do excedente consumido improdutivamente seja de $\mathrm{U} / \mathrm{S}=50 \%$, a escala de insumo de $t+1$, no lugar de ser $I_{t+1}$, será de apenas $I_{t+1}^{\prime}$ e o produto bruto de $t+1$ será de apenas $\mathrm{O}_{t+1}^{\prime}$ e não de $\mathrm{O}_{t+1}$. Portanto, pode-se concluir que o consumo improdutivo faz declinar a taxa de crescimento do produto bruto e que a taxa de crescimento do produto reprodutivamente útil (linha $\mathrm{O}^{\prime \prime} \mathrm{U} / \mathrm{S}=50 \%$ ) cai para uma taxa abaixo da taxa do crescimento do produto bruto. Mostra-se também que quanto menor é o crescimento do produto, menor o aumento na demanda (M) necessária para sustentá-lo.

“A elevação da taxa de consumo improdutivo de maneira nenhuma desenvolve as 'forças de produção' de Malthus. Pelo contrário, essa elevação retarda a taxa real de crescimento, promove o acompanhamento inflacionário dessa retardação, e 
finalmente, conjuga-se com a crescente composição do valor do capital para baixar a taxa geral do lucro." 22

$\mathrm{Na}$ fase do capitalismo maduro, o impulso para acumular recai sobre a acumulação de capitais da intermediação em empregos circulatórios. O mecanismo de alocação de investimentos no capitalismo conduz sempre de setores e ramos onde, por qualquer razão, a taxa de lucro está em declínio para setores e ramos onde o progresso da técnica cria uma perspectiva de taxa de lucro mais elevada. De uma forma perversa para o sistema, no capitalismo maduro, o mecanismo leva o capital para campos inteiramente improdutivos. Um aumento secular na taxa de consumo improdutivo não está apenas associado à ascensão do militarismo, imperialismo, guerra, etc., senão também a um sistema de "bem-estar" e a uma aceleração relativa na acumulação de capitais circulatórios.

Em vista das constantes dificuldades que o capitalismo mundial enfrenta para sair da crise, não seria surpreendente que o desenvolvimento excessivo do trabalho improdutivo e seus consumos contribuísse mais do que qualquer outra coisa para intensificar a tendência à queda da taxa geral de lucro, para a estagnação econômica e, eventualmente, para o colapso do modo de produção capitalista.

Em síntese, a aceleração do ritmo de inflação dos países desenvolvidos, a redução na produção industrial mundial e nas taxas de utilização da capacidade instalada, a queda generalizada dos PNBs mundiais na última década, o aumento alarmante das taxas de desemprego e o aumento na taxa de consumo improdutivo indicam que enfrentamos uma das crises mais sérias do capitalismo, de caráter estrutural, que poderá perdurar ainda por um período prolongado. A inversão da tendência, dentro da lógica capitalista, exigiria mudanças substanciais a nível econômico, político e social.

\section{2 - SAIDA DA CRISE}

Para termos um aumento sustentado na taxa de lucro que possibilite uma recuperação da economia capitalista por um período prolongado e não apenas recuperações espasmódicas de curta duração, seria necessária a ocorrência simultânea de uma série de fatores.

22 - BECKER, James F. Op. cit., p. 230. 
1 - Uma queda importante no preço das matérias-primas, inclusive no preço da energia. É preciso, contudo, que tenha escala para produzir efeitos no conjunto. Em 1982, houve uma queda de $15 \%$ nos preços do petróleo, mas os preços têm-se mantido firmes este ano e parece bastante improvável que se verifiquem quedas importantes nos próximos anos, uma vez que isso afetaria a rentabilidade de uma série de investimentos em fontes energéticas alternativas. Porém, o índice The Economist do preço das "commodities" não-petróleo elevou-se em $28 \%$ nos últimos 12 meses. ${ }^{23}$

2 - Uma nova redução no valor dos elementos do capital fixo. A terceira revolução tecnológica tinha conseguido frear o aumento da composição orgânica do capital no pós-guerra. Na crise atual, o ritmo de crescimento da produtividade do trabalho tem sido mais lento, tanto no Departamento I, quanto no Departamento II. Isso levou a um encarecimento progressivo do capital fixo e a uma redução na taxa de mais-valia relativa.

3 - Uma desvalorização massiva dos capitais, seja por uma queda dos preços das mercadorias (muito improvável, devido a que os monopólios fixam o preço de um grande número de produtos e bloqueiam a baixa, favorecendo justamente o caráter inflacionário do capitalismo tardiol, seja em conseqüência de falências comerciais e do fechamento de empresas, destruindo-se grande parte do valor do seu capital.

A inflação e o crédito crescentes impediram esse saneamento da economia capitalista, adiando de certa forma um colapso maior. Por sua vez, a capacidade de endividamento das empresas e das famílias está atingindo níveis insustentáveis, e uma onda de falências, não apenas de pequenas e médias empresas, senão também dos grandes conglomerados, poderá aprofundar a crise para permitir uma recuperação posterior num patamar mais elevado de concentração e centralização. Não se sabe até quando o sistema bancário e os poderes públicos continuarão subsidiando os grandes trusts que trabalham em déficit. "Hoje, 1700 grandes empresas e multinacionais produzem $60 \%$ da produção industrial do mundo. Vão ser reduzidas para 700. Na indústria automobilística, tem 7 ou 8. Vão ficar três". ${ }^{24}$

4 - Um aumento da taxa de mais-valia possibilitado pelo desemprego estrutural. Vimos, na análise da crise atual, que o núme-

23 - O buraco é mais fundo. Senhor, São Paulo, Três, (134):44, 12 out. 1983.

24 - Declarações do professor Joâo Manoel Cardoso de Mello, da Unicamp, para o jornat Zero Hora, Porto Alegre, 18/9/83. 
ro de desempregados aumenta ano após ano. Inclusive nos anos de reativação da produção industrial o número de desempregados fica estabilizado, mas não diminui. O desemprego e o medo ao desemprego aumentam a "disciplina do trabalho", reduzem as flutuações de mão-de-obra e facilitam a intensificação do processo do trabaIho. ${ }^{25}$

Embora o que diferencia a crise atual da situação de 1929 . 1932 seja a forte organização operária, a força numérica e a sua combatividade numa época de enfraquecimento político do sistema burguês, nada garante que, se esta situação se prolongar, não ocorra um importante desmantelamento das vantagens sociais indiretas e eventualmente uma redução do poder de barganha dos sindicatos que os leve a aceitar salários mais baixos para garantir o emprego. A expansão do exército industrial de reserva nos próprios países imperialistas poderá eventualmente modificar a relação de forças em benefício do capital.

5 - A nova divisão internacional do trabalho, transferindo para a periferia algumas indústrias que utilizam mão-de-obra abundante e barata na sua produção. E o caso do México, que abriga um número importante de indústrias na sua fronteira com os Estados Unidos, é o caso dos inúmeros investimentos na América Latina e na Asia.

Esta tendência, que parecia muito clara na década de 70 , hoje em dia parece ter perdido impulso e enfrenta o crescente protecionismo das nações e a própria estagnação do mercado mundial.

6 - Sem dúvida, a saída mais convincente para a crise atual fica no campo de uma nova revolução tecnológica centrada provavelmente em três ramos fundamentais: a eletrônica (automação), a engenharia genética e novas formas de energia. Os microprocessadores, os robôs industriais e domésticos, os carros elétricos e de energia solar terão lugar de destaque nesta passagem da semiautomação para uma automação mais completa.

\section{3 - CONSEQÜENCIAS}

Um dos problemas mais sérios que tende a se agravar na totalidade dos países imperialistas é o problema do desemprego. Vários fatores se conjugam para explicar o crescimento constante do

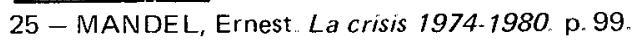


desemprego. Em primeiro lugar, a desaceleração geral e a longo prazo do crescimento econômico. Essa desaceleração coincide com um avanço tecnológico pronunciado, isto é, com um aumento da produtividade média do trabalho. Significa que o número de horas de trabalho necessário para produzir mercadorias e serviços em estagnação, recuo, ou progressão muito lenta é cada vez menor. A isso devemos acrescentar que a correlação entre os investimentos e a criação de emprego foi rompida, sendo que muitos desses investimentos de racionalização suprimem empregos em lugar de criá-los.

As novas mudanças tecnológicas proporcionarão "uma economia de trabalho da ordem de 30 a $35 \%$ na indústria e 35 a $40 \%$ no serviço. Só nos serviços pessoais, nos próximos dez anos nos Estados Unidos, vão ser destruídos 13 milhões de empregos". ${ }^{26}$ Isto significa que o setor terciário (ou dos serviços) que nas décadas passadas foi um forte criador de empregos e absorveu os trabalhadores liberados pela industrialização na agricultura e a semi-automação na indústria não desempenhará mais aquele papel de "refúgio". Pelo contrário, o setor terciário, em lugar de compensar as perdas de emprego realizadas na produção material, passará a ser, por sua vez, uma fonte de desemprego.

\section{“Uma análise da Organização Internacional do Trabalho (OIT) estima que a Europa, por causa da automação, terá 20 mi- Thões de desempregados em 1990 (14\% da população econo- micamente ativa)" ${ }^{27}$}

Vimos que a crise é grave e longa. Contrariamente ao que aconteceu depois da recessão de 1974-75, os países imperialistas terão menos possibilidades de encontrar nos países semicoloniais e nos países socialistas os "mercados de substituição" que possam atenuar a queda do volume de comércio entre os próprios países da OCDE. O endividamento externo dos países do Terceiro Mundo que estimulou as importações de manufaturas procedentes das economias industrializadas alcançou hoje cifras astronômicas. "A dívida acumulada desse grupo de países superou o meio trilhão de dólares ao final de 1982." 28

A partir do anúncio da moratória do México, em agosto de 1982, os empréstimos dos grandes bancos sofreram um brusco re-

26 - Declarações do professor João Manoel Cardoso de Mello, da Unicamp, para o jornal Zero Hora, Porto Alegre, 18/9/83.

27 - Exame, (280):24, 13 jul. 1983.

28 - FURTADO, Celso. A crise da economia capitalista. Revista de Economia Política, São Paulo, Brasiliense, 3 (2) :9, abr “/jun. 1983. 
traimento. A inexistência de um "prestamista de último recurso" ou de uma banca central mundial evidenciou mais uma vez a vulnerabilidade crescente do sistema internacional de crédito.

\section{CONCL.USÃO}

Historicamente as crises mais sérias do capitalismo se resolveram por meio da expansão dos mercados, das guerras e das revoluções tecnológicas. No momento, tecnicamente existem possibilidades de introduzir inovações tecnológicas em grande escala. O maior obstáculo que se levanta para sua difusão é o nível demasiado baixo da taxa de lucro e um mercado estagnado, com uma grande reserva de capacidade ociosa. Esta situação poderá retardar por um bom tempo a revolução tecnológica. As comoções sociais que uma prolongada depressão e desemprego poderão causar não apenas nos paises imperialistas mas também nos países do Terceiro Mundo aumentam os riscos de uma utilização maciça do vultoso arsenal de armamentos. 